\title{
The Origin of Thalamic Inputs to the "Hand" Representation in the Primary Motor Cortex
}

\author{
James W. Holsapple,' James B. Preston, ${ }^{2}$ and Peter L. Strick ${ }^{1,2,3}$ \\ Departments of 'Neurosurgery and ${ }^{2}$ Physiology, SUNY Health Science Center at Syracuse, Syracuse, New York 13210 \\ and ${ }^{3}$ Research Service, Veterans Administration Medical Center, Syracuse, New York 13210
}

\begin{abstract}
We used retrograde transport of WGA-HRP to examine the origin of thalamic inputs to the "hand" representation in the primary motor cortex of macaques (Macaca nemestrina). Injections were placed in either the crest of the precentral gyrus or the rostral bank of the central sulcus. The sites for injection in the sulcus were determined by using intracortical stimulation to map the location of hand representation.

We found that the precentral gyrus and central sulcus receive their predominant input from different subdivisions of the ventrolateral thalamus. Ventralis posterior lateralis pars oralis (VPLo) provides the most substantial input to a portion of the hand representation on the gyrus. In contrast, Ventralis lateralis pars oralis (VLo) provides the most substantial input to a portion of the hand representation in the sulcus. Prior studies have shown that VPLo is a major site of termination of cerebellar efferents and that VLo is a major site of termination of pallidal efferents. Thus, our results indicate that both the basal ganglia and the cerebellum "directly" influence the "hand" representation of the primary motor cortex.
\end{abstract}

Despite numerous studies, the origin of thalamic inputs to the primary motor cortex remains controversial. Although there is general agreement that one subdivision of the ventrolateral thalamus, ventralis posterior lateralis pars oralis (VPLo), has substantial projections to the primary motor cortex, the extent of projections from another subdivision, ventralis lateralis pars oralis (VLo), is disputed. Early studies using retrograde tracers reported that the primary motor cortex receives thalamic input from VPLo, VLo, and two other subdivisions of the ventrolateral thalamus: ventralis lateralis pars caudalis (VLc) and ventralis lateralis pars medialis (VLm; e.g., Strick, 1975, 1976; Kievit and Kuypers, 1977; see also Kunzle, 1976). On the other hand, Jones et al. (1979) concluded that projections from the ventrolatcral thalamus to the primary motor cortex originates only from VPLo and VLc. In fact, they specifically stated that no labeling was found in VLo following tracer injections into the primary motor cortex. The reasons for this disparity have not

\footnotetext{
Received Jan. 17, 1991; revised Mar. 22, 1991; accepted Mar. 26, 1991.

This work was supported by funds from the Veterans Administration Medical Research Service and by U.S. Public Health Service Grants 02957, 24328, and 843902. We wish to thank Mr. Mike Page for development of computer programs and Ms. Mary Lou Cherney and Sarah Fitzpatrick for their expert technical assistance.

Correspondence should be addressed to Dr. Peter L. Strick, Research Service (151), Veterans Administration Medical Center, Syracuse, NY 13210.

Copyright (C) 1991 Society for Neuroscience 0270-6474/91/112644-11\$03.00/0
}

been discovered in subsequent studies (e.g., Miyata and Sasaki, 1983; Schell and Strick, 1984; Wiesendanger and Wiesendanger, 1985; Leichnetz, 1986; Ghosh et al., 1987; Matclli ct al., 1989; Orioli and Strick, 1989; Darian-Smith et al., 1990).

The issue of thalamocortical connectivity is particularly relevant to concepts about the function of cerebellar and basal ganglia loops with the cortical motor areas (e.g., Evarts and Thach, 1969; Kemp and Powell, 1971; Allen and Tsukahara, 1974; Brooks and Thach, 1981; Alexander et al., 1986; Dum and Strick, 1991a). Efferents from all three deep cerebellar nuclei terminate densely in VPLo, but avoid VLo (e.g., Mehler, 1971; Kievit and Kuypers, 1972; Batton et al., 1977; Chan-Palay, 1977; Percheron, 1977; Stanton, 1980; Kalil, 1981; Asanuma et al., 1983b). Thus, thalamocortical projections from VPLo are thought to provide cerebellar efferent systems with "direct" access to the primary motor cortex. On the other hand, efferents from the internal segment of the globus pallidus terminate densely in VLo, but avoid VPLo (e.g., Nauta and Mehler, 1966; Kuo and Carpenter, 1973; Kim ct al., 1976; DeVito and Anderson, 1982; Ilinsky and Kultas-Ilinsky, 1987). If, as some have suggested, VLo does not innervate the primary motor cortex, then there is no route available through the ventrolateral thalamus for the basal ganglia to gain "direct" access to this cortical area. Clearly, the resolution of the controversy regarding the projections of VLo to the primary motor cortex has important implications for theories about the motor functions of the basal ganglia.

One source of this controversy may be that the primary motor cortex is not a homogeneous cortical field. As a result, thalamic inputs to different sites within the primary motor cortex may vary (e.g., Matelli et al., 1989). Mapping studies in both oldand new-world monkeys have found that rostral and caudal portions of the hand representation in the primary motor cortex receive distinct patterns of peripheral afferent input (Strick and Preston, 1978a,b, 1982a,b; Lamour et al., 1980; Lemon, 1981; see also Tanji and Wise, 1981, for comparable results in hindlimb representation of motor cortex). Motivated by these findings, we have begun to examine the connections of rostral and caudal portions of the hand representation in the primary motor cortex of macaques. Our results indicate that these portions of the hand representation receive their predominant input from different subdivisions of the ventrolateral thalamus. Furthermore, we found that VLo provides the most substantial thalamic input to the caudal portion of the hand representation, which lies in the central sulcus. This result suggests that VLo provides the basal ganglia with direct access to the primary motor cortex.

An abstract of these results has been presented previously (Holsapple et al., 1990). 


\section{Materials and Methods}

Experiments were performed on three monkeys (Macaca nemestrina). In two animals (OM2 and OM4), the portion of the hand representation of primary motor cortex that is buried in the anterior bank of the central sulcus was mapped using intracortical stimulation. This region was then injected with wheat germ agglutinin conjugated to horseradish peroxidase (WGA-HRP). In the third animal (J14), injections of diamidino yellow (DY) were placed into the portion of the hand representation of the primary motor cortex, which is located on the crest of the precentral gyrus.

\section{Surgical procedures}

All procedures were performed using sterile techniques. Twelve hours before surgery, an animal was pretreated with dexamethasone $(0.5 \mathrm{mg} /$ $\mathrm{kg}, \mathrm{i} . \mathrm{m}$.), and its food and water were restricted. The animal was anesthetized with a combination of ketamine $\mathrm{HCl}(25 \mathrm{mg} / \mathrm{kg}$, i.m.) and pentobarbital $\mathrm{Na}(20 \mathrm{mg} / \mathrm{kg}$, i.p.). Supplemental doses of ketamine were given as needed during each experiment. The level of anesthesia was maintained such that a slight withdrawal reflex could be elicited. On the day of surgery, each animal received dexamethasone $(0.5 \mathrm{mg} / \mathrm{kg}$, i.m.), atropine $(0.05 \mathrm{mg} / \mathrm{kg}$, i.m.), and antibiotics (Gentamicin, $1 \mathrm{mg} / \mathrm{kg}$ every $8 \mathrm{hr}$ ). Temperature was monitored continuously during the surgery using a rectal probe and was maintained between $37^{\circ} \mathrm{C}$ and $38.5^{\circ} \mathrm{C}$ with a heating pad.

$O M 2$ and OM4. The preparation and procedures we employed for physiological mapping in OM2 and OM4 have been described previously (Strick and Preston, 1982a,b). Briefly, a bolt was secured to the skull with dental acrylic to hold the animal's head. The skull over the forelimb area of motor cortex was removed, and a plastic cylinder was affixed over the craniotomy. The exposed dura was removed, and the cylinder was filled with warm surgical-grade silicone (Dow Corning, $1500 \mathrm{cSt}$ ). The chamber was sealcd with a clcar Plexiglas lid to which a microdrive was attached.

Glass-coated Elgiloy microelectrodes (Suzuki and Azuma, 1976; impedance, $0.6-1.4 \mathrm{M} \Omega$ at $1 \mathrm{kHz}$ ) were advanced by the microdrive through a small hole in the Plexiglas lid. The site of each microelectrode penetration was observed through a dissecting microscope and marked on an enlarged photograph of the brain. A series of electrode penetrations $[n=10$ (OM2), 11 (OM4)] were made into the anterior bank of the central sulcus. Cathodal stimulation (12-20 pulses, 0.2 -msec duration, $300-350-\mathrm{Hz}$ frequency, $1-30-\mu \mathrm{A}$ intensity) was delivered every $100-$ $200 \mu \mathrm{m}$ beginning at $1.5 \mathrm{~mm}$ below the cortical surface and extending for $6-8 \mathrm{~mm}$ into the sulcus. The stimulus intensity was continuously monitored by an isolated "passive current probe," which measures the current passing through the wire to the microelectrode. As in our earlier studies (Strick and Preston, 1982a,b), the motor response at each site was the movement evoked at threshold. Threshold was defined as the stimulus intensity that evoked movement in $50 \%$ of the trials. Visual observation and muscle palpation were used to define responses.

When the physiological mapping was completed, the appropriate site in the sulcus was injected with WGA-HRP (Sigma; $2 \%$ in $0.5 \mathrm{M} \mathrm{NaCl}$ with $0.1 \mathrm{M}$ mannose) using a Hamilton syringe with a 26-gauge fixed needle. In OM2, $0.075 \mu \mathrm{l}$ was injected at each of two sites, 3.5 and 4.5 $\mathrm{mm}$ below the cortical surface. In OM4, $0.05 \mu \mathrm{l}$ was injected at a single site $4.8 \mathrm{~mm}$ below the cortical surface. The needle was left in place for approximately $2 \mathrm{~min}$ after each injection. When the injections were completed, the recording chamber was emptied of silicone, filled with $2.5 \%$ agar, and capped. The animal was then returned to its home cage.

J14. In J14, a bone flap was removed over the arm area of the primary motor cortex, and the dura was opened. The cortex was covered with warm silicone to prevent it from drying. The central, arcuate, and superior precentral sulci were visualized. In order not to interfere with unrelated experiments in the opposite hemisphere, no electrophysiological mapping was performed in this animal. Therefore, the location of the hand area on the crest of the precentral gyrus was determined using these surface landmarks (Woolsey et al., 1952; Kwan et al., 1978; Sessle and Wiesendanger, 1982). Three injections of DY ( $2 \%$ suspension in $0.2 \mathrm{M}$ phosphate buffer at $\mathrm{pH} 7.2,0.3 \mu \mathrm{l} /$ site; Keizer et al., 1983) were placed into this region. The injections were made $1.5-2 \mathrm{~mm}$ below the cortical surface and were spaced approximately $1 \mathrm{~mm}$ apart and 3 $\mathrm{mm}$ anterior to the central sulcus. When the injections were completed, the bone flap was repositioned, the skin was closed, and the animal was returned to its home cage.
After a survival period of $3 \mathrm{~d}$ (OM2, OM4) or $7 \mathrm{~d}$ (J14), all animals were reanesthetized and perfused transcardially using a four-stage procedure (Rosene and Mesulam, 1978; Mesulam, 1982). The perfusates included (1) $0.1 \mathrm{M}$ phosphate buffer, $\mathrm{pH} 7.4$; (2) $2.5 \%$ paraformaldehyde in $0.1 \mathrm{M}$ phosphate buffer; (3) $2.5 \%$ paraformaldehyde in $0.1 \mathrm{M}$ phosphate buffer with $10 \%$ glycerin; and (4) $0.1 \mathrm{M}$ phosphate buffer with $10 \%$ glycerin. Following the perfusion, each brain was stored in $0.1 \mathrm{M}$ phosphate buffer with $10-20 \%$ glycerin at $4^{\circ} \mathrm{C}$ for $7-10 \mathrm{~d}$.

\section{Histological procedures}

The brain was quick frozen in cold isopentane (Rosene et al., 1986), and serial sections $(50 \mu \mathrm{m})$ were cut in the frontal plane on a microtome. Every tenth section was postfixed and processed for cytoarchitecture (E. C. Gower, in Mesulam, 1982). The remaining sections of OM2 and OM4 were processed for HRP by the tetramethylbenzidine (TMB) method according to Mesulam (1982) and Gibson et al. (1984), with only minor modifications. Every other section of J14 was immediately mounted and air dried for examination under fluorescent illumination.

\section{Analytical procedures}

The outlines of sections and the location of injection sitcs, labcled ncurons, and tissue landmarks (e.g., blood vessels) were plotted and stored using a computerized charting system (Minnesota Datametrics). This system uses optical encoders to sense $x-y$ movements of the microscope stage and stores the coordinates of charted structures (e.g., labeled neurons, section outlines). At least every eighth serial section was plotted throughout the injection site and thalamus of each animal. Sections were studied microscopically using fluorescent illumination (Leitz filter A, 360-nm excitation wavelength) for DY labeling and brightfield and darkfield illumination with polarized light for WGA-HRP labeling.

WGA-HRP injections sites were considered to include the densely stained regions adjacent to each needle track, but not the adjacent region with light background staining where individual neurons could be distinguished (Mesulam, 1982). DY injection sites were considered to include the central mass of brown-yellow fluorescent material that surrounded each needle track, but not the adjacent region that contained a dense accumulation of fluorescent nuclei of neurons and glia (Keizer et al., 1983; Conde, 1987).

After a section through the thalamus was plotted for labeled neurons, its coverslip was removed; the section was counterstained with cresyl violet and recoverslipped. The counterstained section was aligned with the plot of labeled neurons using the charting system, along with section outlines and tissue landmarks. Then, cytoarchitectonic borders and the outlines of unique features in specific subdivisions in the ventrolateral thalamus (e.g., cell clusters in VLo) were added to the plot of labeled neurons. Computer programs were written to examine the plots of each section and determine the number of labeled neurons in each thalamic subdivision. This analysis was performed on approximately 20 sections spaced at $400-\mu \mathrm{m}$ intervals through the thalamus of each animal.

All surgical and experimental procedures were approved by the appropriate institutional animal care and use committees.

\section{Results}

\section{Location and extent of injection sites}

\section{Sulcus injections}

We made a limited number of microelectrode penetrations into the anterior bank of the central sulcus of OM2 and OM4 to locate the hand representation in this region of cortex (Fig. 1, bottom). The goal of mapping was to provide a physiological control for tracer injections and yet preserve the histology of this region of cortex. In both animals, we found that intracortical stimulation evoked movements of the fingers and wrist (Fig. 1, solid and open circles) from a broad region of the anterior bank of the central sulcus. This region of hand representation measured greater than $3 \mathrm{~mm}$ in the mediolateral direction and greater than $4 \mathrm{~mm}$ in depth.

Injections of $2 \%$ WGA-HRP were placed at the center of the physiologically defined region of digit representation in the sul- 
Figure 1. Location of cortical injection sites and microstimulation maps. $T o p$, Lateral view of hemisphere with the anterior bank of central sulcus exposed. The injection sites of three animals $(O M 2, O M 4$, and $J 14)$ are plotted on a single hemisphere. The spread of tracer (WGA-HRP: OM2, OM4; DY: $\mathrm{J} 14$ ) at each site is outlined by a thick solid line. Bottom, Maps of the motor responses evoked by intracortical stimulation in the rostral bank of the central sulcus. The shaded areas indicate the spread of tracer. Vertical lines indicate electrode tracks. Asterisks mark entry points on the precentral gyrus for each electrode track. The plus sign in each panel indicates the entry point on the gyrus for the needle that injected tracer. The broken lines indicate bottom of central sulcus. Responses evoked by stimulation: solid circles, finger movements; open circles, wrist movements; open triangles, elbow movements; open squares, shoulder movements. Note that each injection site is centered in the region where finger and wrist movements were evoked. $A r S$, arcuate sulcus; $C S$, central sulcus; $S p C s$, superior precentral sulcus. The intervals between the tick marks at the edges are $1 \mathrm{~mm}$.

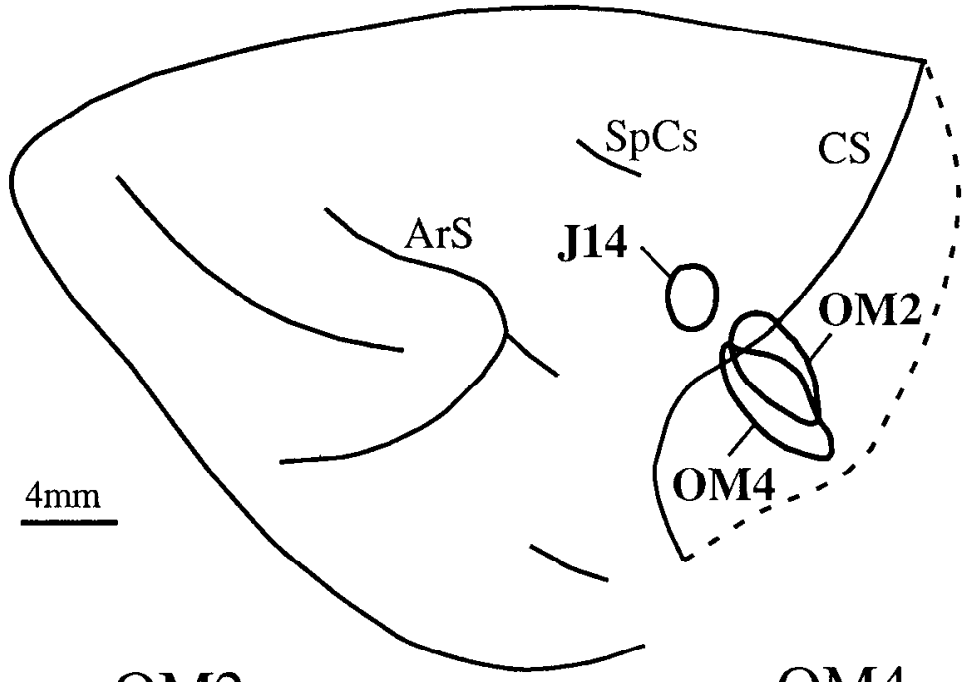

$\mathrm{OM} 2$
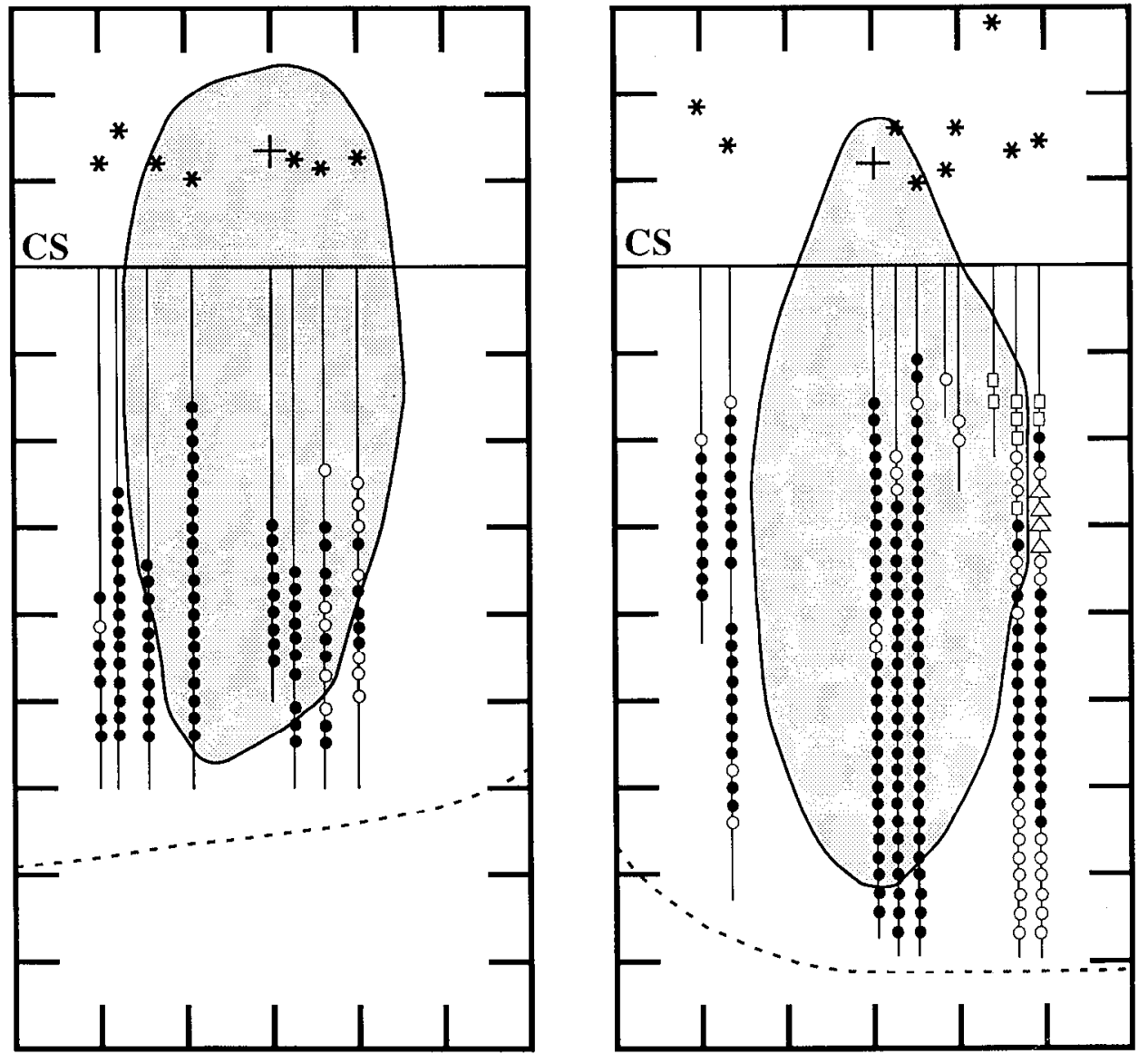

cus (Fig. 1, shaded areas). The injection in OM4 was located in the middle third of the sulcus, and the two injections in OM2 were located in the middle and upper thirds. In both cases, the spread of tracer in the sulcus was confined to the mapped region and involved sites where stimulation evoked largely hand movements (Figs. 1, 2). In addition, tracer spread up the needle track to involve a small portion of the adjacent precentral gyrus.

\section{Surface injection}

In case $\mathrm{J} 14$, three closely spaced injections of $2 \% \mathrm{DY}$ were placed into the crest of the precentral gyrus approximately $3 \mathrm{~mm}$ anterior to the central sulcus (Figs. 1,2). Tracer spread to involve a roughly circular region of the precentral gyrus that measured approximately $4 \mathrm{~mm}$ in diameter. The area of cortex containing tracer was largely confined to a region that all published maps of the primary motor cortex in macaques include within the representation of the fingers and wrist (e.g., Woolsey et al., 1952; Kwan et al., 1978; Sessle and Wiesendanger, 1982; Sato and Tanji, 1989).

\section{Thalamic cytoarchitecture}

In general, we will employ the atlas and terminology of Olszewski (1952) to describe the topographic distribution of labeled neurons within the ventrolateral thalamus. However, as in a 


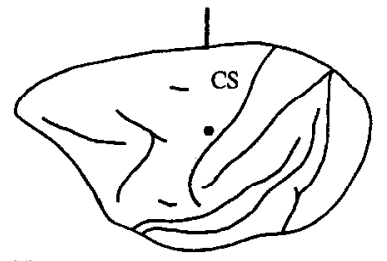

$15 \mathrm{~mm}$

OM2
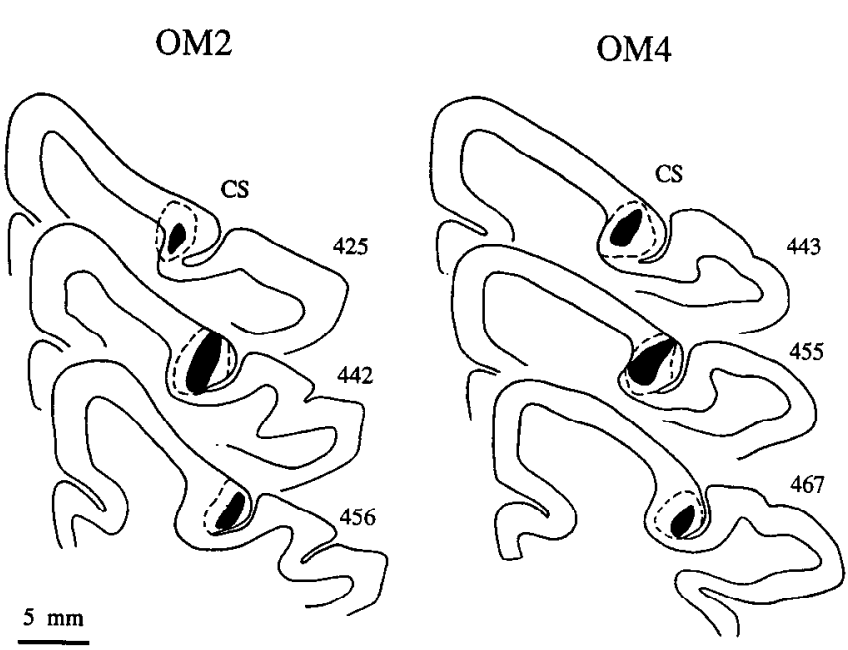

OM4
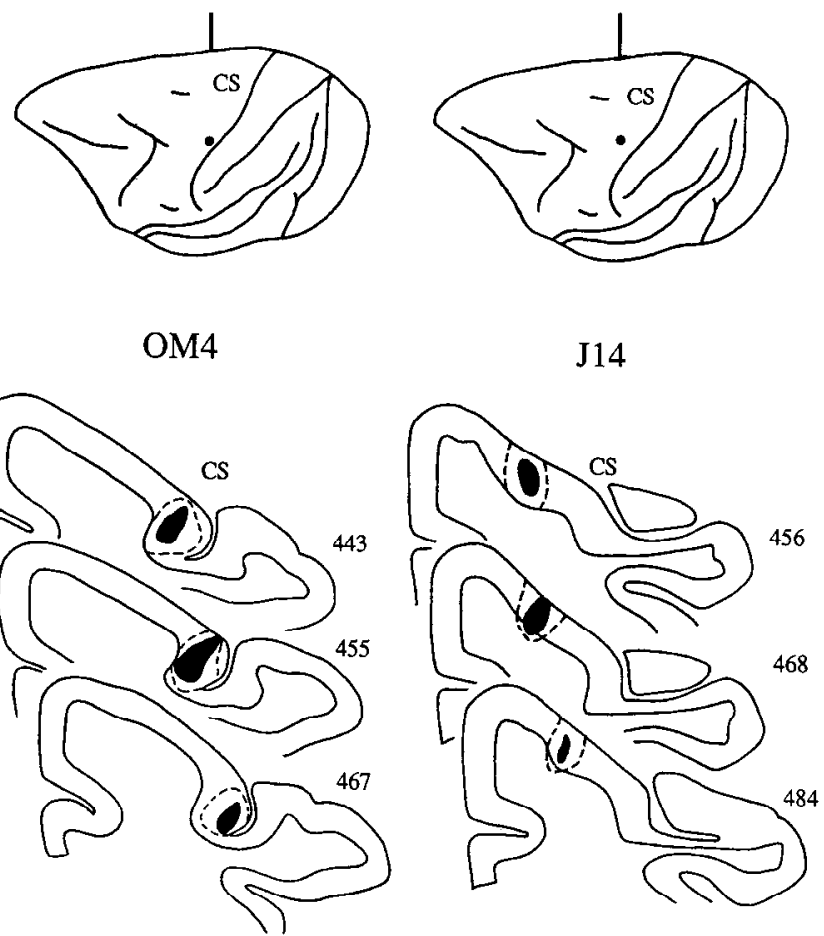

Figure 2. Cross sections through the injection sites. Top, Lateral view of the left hemisphere. The solid circle on each brain outline indicates the entry point of the needle that injected tracer. The vertical line on each diagram marks the approximate rostrocaudal level of sections shown below. Bottom, Coronal sections through each injection site. The solid area on cach section indicates the location of the injection site. The broken lines indicate the halo of tracer that surrounded each injection site. See Results for details. The section number of each $50-\mu \mathrm{m}$-thick section is indicated at the lower right of each outline. CS, central sulcus. prior publication (Schell and Strick, 1984), we have modified some of the borders between the various thalamic subdivisions (see also Wiesendanger and Wiesendanger, 1985; Matelli et al., 1989). We will review the features that characterize one subdivision, VLo, because this subdivision is particularly relevant to the present study and its definition has been the subject of some controversy (e.g., Wiesendanger and Wiesendanger, 1985).

VLo is characterized by clusters of large- to medium-sized neurons that stain darkly for Nissl substance (Fig. 3). At its core, the clusters of VLo neurons are packed tightly together and form a continuous slab. At more caudal levels, the cell clusters are more loosely arranged and are separated by regions of lower cell density (i.e., the "cell-sparse zones" of Asanuma et al., 1983a). In fact, these regions of low cell density expand at caudal levels and divide VLo into clcar dorsal and ventral sectors. Lateral to VLo is another region of low cell density that contains some large, darkly staining neurons, but lacks cell clusters. This region has been included within VPLo (Schell and Strick, 1984).

The source of the controversy regarding this thalamic subdivision is whether or not both the regions of low cell density and the cell clusters should be included within the borders of VLo. This issue is important because of the suggestion (Wiesendanger and Wiesendanger, 1985) that early reports of a projection from VLo to area 4 (Strick, 1975, 1976; Kunzle, 1976; Kievit and Kuypers, 1977; Kalil, 1978; Miyata and Sasaki, 1983) may have been based on the inclusion of both regions within VLo. Olszewski's (1952) original definition of VLo included the low-cell-density regions along with the cell clusters. However, based on connectional data, more recent studies have limited the definition of VLo to the cell clusters and included the regions of low ccll density within the borders of VPLo (e.g., Asanuma et al., 1983a; Schell and Strick, 1984). In the present study, we will continue to limit the definition of VI o to the region of cell clusters (Fig. 3).

We have made one additional modification to Olszewski's nomenclature. Several anatomical studies have indicated that rostral and caudal portions of VLc receive different subcortical inputs. The caudal portion of VLc (VLcc) is clearly a target of cerebellar efferents (e.g., Percheron, 1977; Stanton, 1980; Kalil, 1981; Asanuma et al., 1983b). The rostral portion of VLc (VLcr) receives pallidal efferents (e.g., Kuo and Carpenter, 1973; DeVito and Anderson, 1982). There do not appear to be gross cytoarchitectonic differences between VLcc and VLcr. However, the anatomical studies cited above suggest that VLce lies caudal to A7.1 of Olszewski's atlas and that VLcr lies rostral to this level.

\section{Origin of thalamic input to the hand representation in primary motor cortex}

Tracer injections into either the anterior bank of the central sulcus (OM2, OM4) or the crest of the precentral gyrus (J14) labeled neurons at multiple sites within the thalamus (see Fig. 7). In all animals, the majority of the labeled neurons were found within the ventrolateral thalamus ( $>85 \%$; Figs. 4-6). Most of the remaining labeled neurons were located within three midline and intralaminar nuclei: centralis lateralis $(\mathrm{Cl} ; 4-15 \%)$, centrum medianum (CM; $1-4 \%$ ), and medialis dorsalis (MD; $1-2 \%)$. Only a few labeled neurons were seen in regions of the posterior thalamus $(<1 \%)$. Thus, though the hand representation in primary motor cortex receives input from multiple thalamic nuclei, its predominant input is from the ventrolateral thalamus. Wc will focus the remainder of this section on a description of the distribution of labeled neurons within the subdivisions of the ventrolateral thalamus.

\section{Projections to the anterior bank of the central sulcus}

The distributions of labeled neurons in the ventrolateral thalamus were similar in the two animals with tracer injections into the anterior bank of the central sulcus (OM2 and OM4; Figs. 4, 5, 7). More labeled neurons were found in the ventrolateral thalamus of OM2 than in OM4 (6327 vs 2876 neurons). This is not surprising given that two sites were injected with tracer in OM2 while only one was injected in OM4. In both 


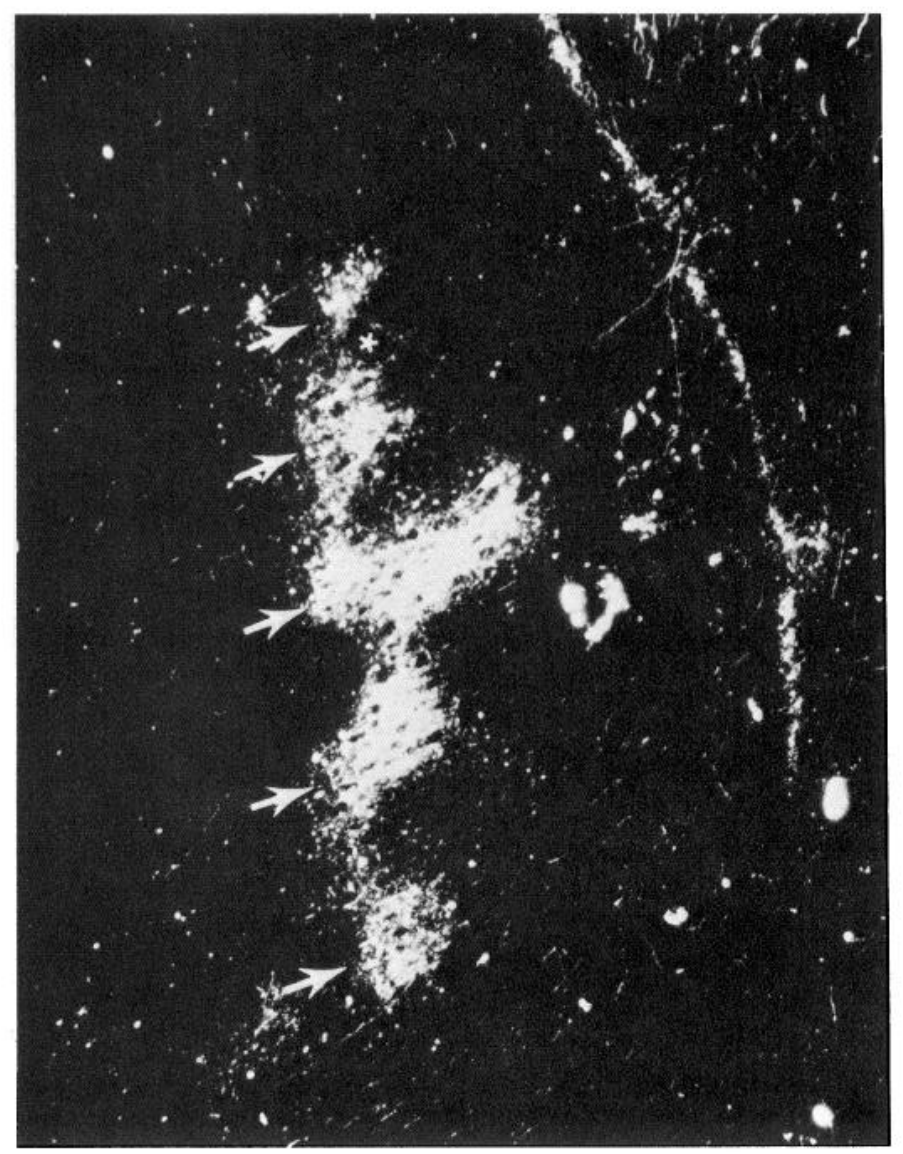

A
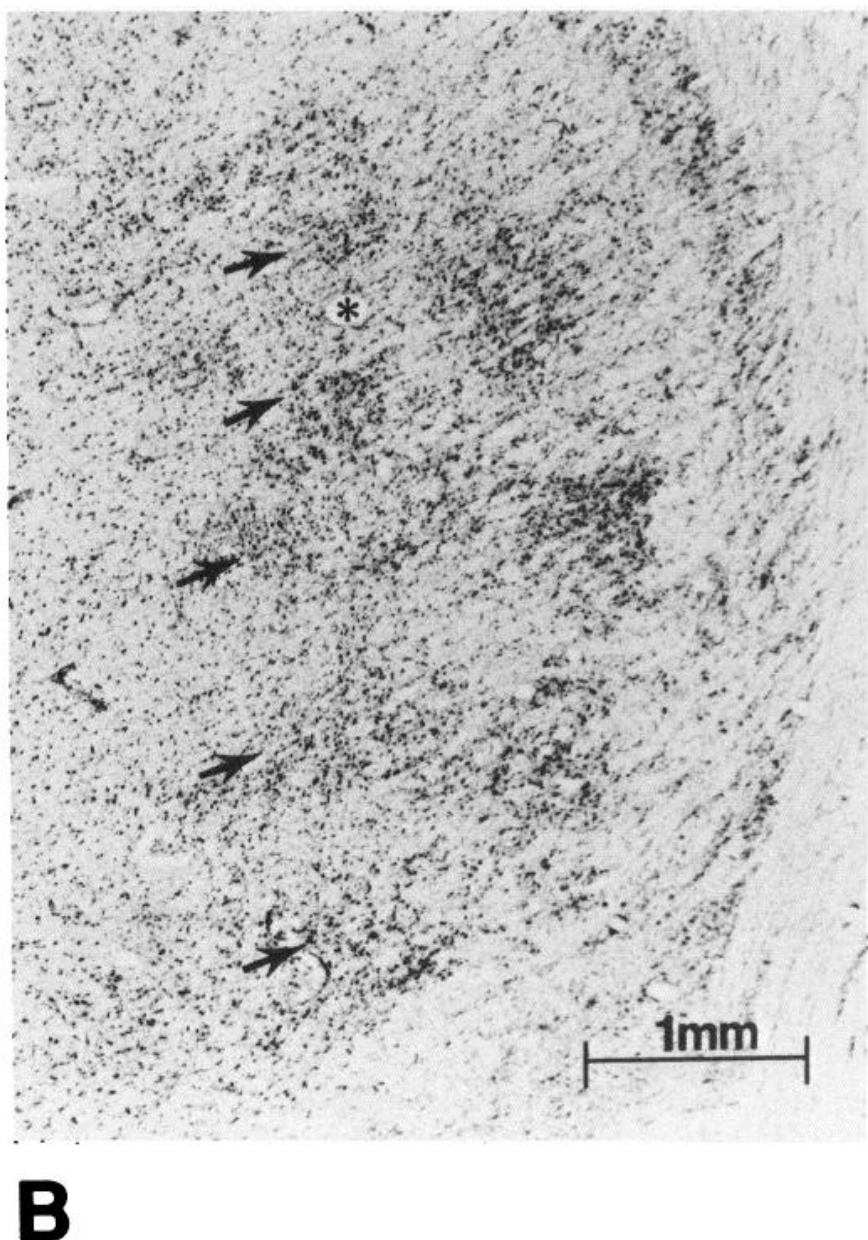

Figure 3. Labeled neurons in VLo. The distribution of labeled neurons is compared with the cytoarchitecture seen on an adjacent section. $A$, Dark-field photomicrograph showing WGA-HRP-labeled neurons (OM4) in VLo. The asterisk here and in $B$ marks the location of a blood vessel used to align the adjacent sections. $B$, Adjacent section stained with cresyl violet. The arrows here and in $A$ indicate the location of five clusters of large, densely stained neurons typical of VLo. Note the correspondence between the labeled neurons and some of the medial cell clusters in VLo at this level (A9.2).

cases, more than half of the labeled neurons were found in a single subdivision of the ventrolateral thalamus, VLo (OM2, $62 \%$; OM4, 54\%). The densest region of labeled neurons in VLo was located between Olszewski's A9.6-A9.2 (Fig. 4, sections 409, 418; Fig. 5, section 447). At this level, some individual cell clusters were intensely labeled (Fig. 3). Few if any labeled neurons were found in the regions of low cell density intercalated between the clusters.

Outside of VLo, the largest number of labeled neurons was found in VPLo (OM2, 23\%; OM4, 37\%; Figs. 4, 5, 7). In OM4, a clear gap separated the labeled neurons in VPLo from those in other subdivisions of the ventrolateral thalamus (Fig. 5, sections 463, 471). A similar but less distinct separation in labeled regions was present in OM2 (Fig. 4, sections 433, 442). Labeled neurons also were consistently found in VLm (OM2, 12\%; OM4, $4 \%$ ). Clearly, the animal with the largest number of labeled neurons in VLm (OM2) also had the largest number of labeled neurons in VLo and the fewest in VPLo. Furthermore, the regions of VLm that contained labeled neurons were continuous with those in VLo (Fig. 4, sections 405, 409, 418; Fig. 5, sections $439,447)$. These observations suggest that a functional relationship may exist between regions of VLo and VLm, but not between regions of VLo and VPLo. Other subdivisions of the ventrolateral thalamus (e.g., VLcc and VLcr) contained relatively few labeled neurons (Fig. 7). In total, the subdivisions of the ventrolateral thalamus that receive pallidal efferents (VLo, VLm, VLcr) contained the clear majority of the labeled neurons (OM2, 75\%; OM4, 61\%). Thus, the most substantial input to the portion of the hand representation in the central sulcus originates from thalamic subdivisions that are the target of basal ganglia output.

\section{Projections to the crest of the precentral gyrus}

The distribution of labeled neurons seen in J14 was similar to that observed in prior studies of thalamic input to the precentral gyrus (e.g., Strick, 1975, 1976; Kievit and Kuypers, 1977; Horne and Tracey, 1979; Jones et al., 1979; Schell and Strick, 1984; Wiesendanger and Wiesendanger, 1985; Matelli et al., 1989). Almost three-fourths of the labeled neurons in the ventrolateral thalamus (547 of 739 neurons) were found in a single subdivision, VPLo (Figs. 6, 7). The densest region of labeled neurons was located between A8.4 and A7.5 of Olszewski's atlas (Fig. 6 , sections 534, 552).

Outside of VPLo, the largest number of labeled neurons was found in VLo (12\%; Figs. 6, 7). The labeled neurons in VLo were typical of the large, darkly staining cells that characterize 


\section{MI - Sulcus (OM2)}
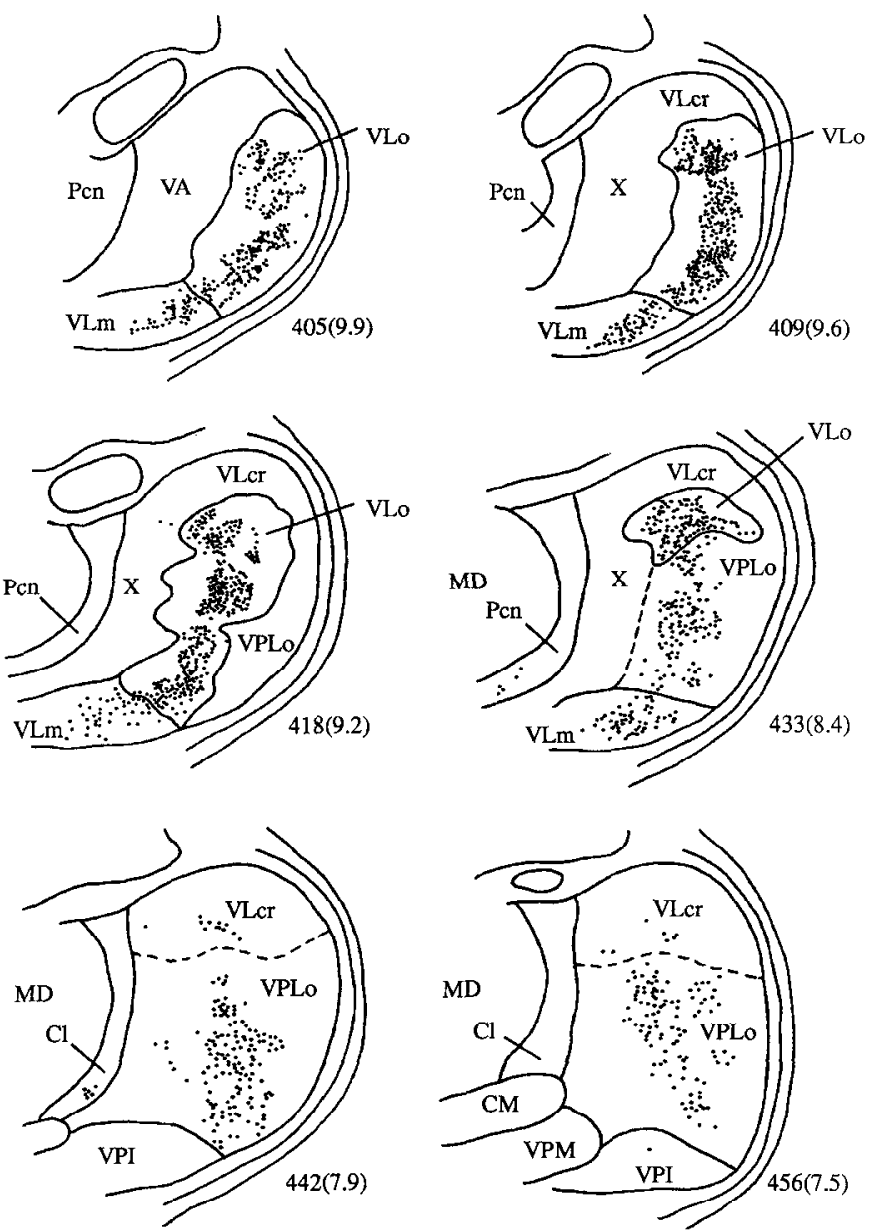

$2 \mathrm{~mm}$

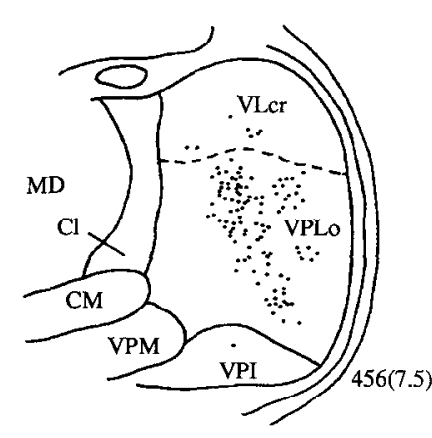

Figure 4. Plots of labeled thalamic neurons in OM2 (WGA-HRP injection into the rostral bank of the central sulcus). The injection site is illustrated in Figures 1 and 2. Labeled neurons on single sections at different levels of the thalamus are indicated by small dots. The section number is indicated at the lower right of each section outline. The numbers in parentheses indicate the approximate level of the section according to Olszewski's (1952) atlas. Note that in OM2 many labeled ncurons are found throughout the rostrocaudal extent of VLo. Some labeled neurons are located in portions of VLm, VLcr, and VPLo. $M I$, primary motor cortex; $P c n$, nucleus paracentralis; $V A$, nucleus ventralis anterior; $X$, area $\mathrm{X} ; V P I$, nucleus ventralis posterior inferior; $V P M$, nucleus ventralis posterior medialis.

this thalamic subdivision. Smaller numbers of labeled neurons were also found in VLm, VLcc, and VLcr (Fig. 7). In total, the subdivisions of the ventrolateral thalamus that receive cerebellar efferents (e.g., VPLo, VLcc) contained a clear majority of the labeled neurons (75\%). Thus, the most substantial input to the portion of the hand representation on the crest of the precentral gyrus originates from thalamic subdivisions that are the target of cerebellar output.

\section{Discussion}

The results of the present study lead to three major conclusions. First, the primary motor cortex is a target of outputs from the basal ganglia, as well as from the cerebellum. Second, outputs from both subcortical systems "directly" influence the hand
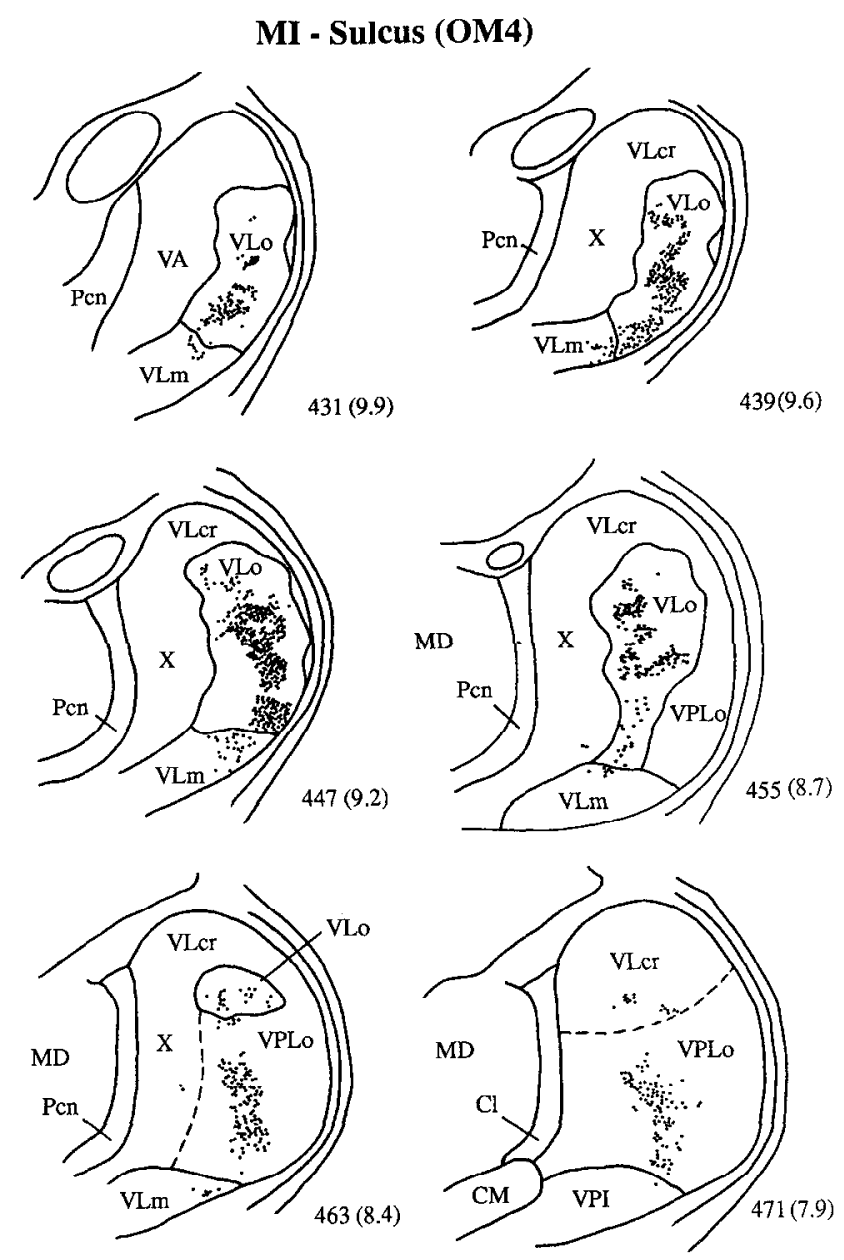

$2 \mathrm{~mm}$

Figure 5. Plots of labeled thalamic neurons in OM4 (WGA-HRP injection into the rostral bank of the central sulcus). The injection site is illustrated in Figures 1 and 2. See Figure 4 for details.

representation of the primary motor cortex. Third, basal ganglia and cerebcllar outputs have largely different patterns of distribution to the hand representation of the primary motor cortex. Before discussing the functional implications of these conclusions, we will examine the relation between the present findings and those of prior studies.

\section{VPLo and VLo projections to primary motor cortex}

Although there has been controversy about the origin of thalamic input to the primary motor cortex (see introductory remarks), there is general agreement that VPLo provides the major input to the portion of the arm representation on the crest of the precentral gyrus (e.g., Strick, 1975, 1976; Kievit and Kuypers, 1977; Jones et al., 1979; Schell and Strick, 1984; Wiesendanger and Wiesendanger, 1985; Ghosh et al., 1987; Matelli et al., 1989). Therefore, we examined the thalamic input to this region of cortex in only one animal. Our observation that approximately $75 \%$ of thc labcled ncurons were located in VPLo when a tracer injection was limited to the precentral gyrus is entirely consistent with prior results (Fig. 8).

VPLo also appears to be a major source of input to other portions of the primary motor cortex. For example, Matelli et 

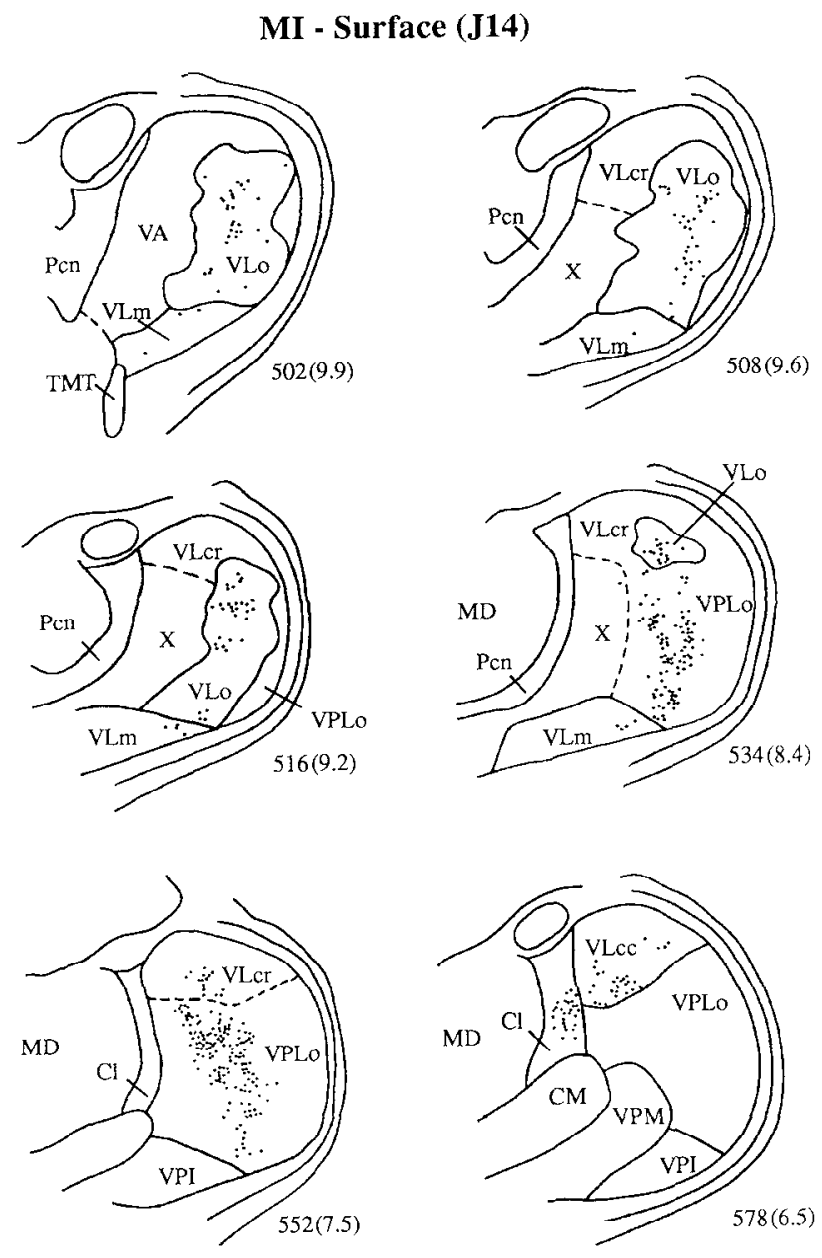

$2 \mathrm{~mm}$

Figure 6. Plots of labeled thalamic neurons in J14 (DY injection into precentral gyrus). The injection site is illustrated in Figures 1 and 2. Note that in J14 many labeled neurons are found in VPLo and few are found in VLo. See Figure 4 for details. TMT, tractus mamillo-thalamicus.

al. (1989) found that around $85 \%$ of the input from the ventrolateral thalamus to the face representation of primary motor cortex originates from parts of VPLo and VLc, and only about $15 \%$ of the input originates from VLo. Clearly, there are portions of the primary motor cortex that receive the majority of their thalamic input from VPLo and only a small component of their input from VLo.

On the other hand, our results indicate that another portion of the primary motor cortex receives its most substantial input from VLo (Fig. 8). We found that VLo contained the majority of the labeled neurons after tracer injections into the hand representation located in the rostral bank of the central sulcus. In fact, in one animal, almost two-thirds of the input originated from this thalamic subdivision. There is no prior suggestion in the literature that VLo is the major source of input to any portion of the distal forelimb representation in the primary motor cortex. Why do our results differ so strikingly from those of prior studies? Unlike other studies, we focused our analysis on a portion of the hand representation that is buried in the anterior bank of the central sulcus. Furthermore, we used intracortical stimulation to define the location of this portion of the hand representation. Thus, the controversy about VLo projections to the primary motor cortex may be due, in part, to differences in the location of the cortical injection sites used to define thalamic inputs.

The existence and extent of projections from VLo to regions of the primary motor cortex other than the hand representation are presently unclear. For example, Matelli et al. (1989) concluded that the "proximal" representation in precentral cortex receives a major thalamic input from VLo. However, this conclusion was based on the results of a single experiment (their monkey IT4-2) in which a tracer injection was placed at a site in the motor cortex where electrical stimulation of the cortical surface evoked movements of the "forearm." Although they found a large number of labeled neurons in VLo in monkey IT4-2, the majority of the labeled neurons in the ventrolateral thalamus $(57 \%)$ were located in VPLo and VLc. Also, tracer spread from the injection site in IT4-2 to involve the anterior bank of the central sulcus. Given our results, some of the labeling in VLo may be due to tracer involvement of the sulcus. We belicve that it is important to note that Matelli ct al. (1989) found more labeled neurons in VLo than in VPLo and VLc only in those cases where tracer primarily involved arm areas rostral to the primary motor cortex (i.e., their cases IT4-6 and IT6-6).

Darian-Smith et al. (1990) reported that, taken together, VLm and VLo provide the majority of the input from the ventrolateral thalamus to "lateral area 4" in adult animals. Surprisingly, they found that their injections into lateral area 4 labeled as many neurons in VLm as in VPLo. In their diagrams, "lateral area 4" appears to be located at the border betwecn the face and forelimb representations. Furthermore, they stated that two of their four injections sites clearly extended into the head representation. Because these authors did not use physiological methods to define the location of their injection sites, it is not clear from their study which parts of the body representation receive substantial input from VLm and which from VPLo and VLo.

Another factor that has complicated the interpretation of results from studies of thalamic input to the primary motor cortex is that more than one definition has been employed to define the exact borders between VLo and VPLo (see Results). For example, Kievit and Kuypers (1977) reported that substantial numbers of neurons were labeled in VLo after tracer injections into the region of primary motor cortex that lies between the distal forelimb and distal hindlimb representations (e.g., their case C8). However, their study used Olszewski's (1952) definition of $\mathrm{VLo}$ that is now thought to include a rostral extension of VPLo (Jones et al., 1979; Schell and Strick, 1984; Wiesendanger and Wiesendanger, 1985; Matelli et al., 1989). Thus, it is uncertain whether the clusters of large, darkly staining neurons that are typical of VLo were labeled in the experiment of Kievit and Kuypers (1977). The same question may be raised about other reports of VLo labeling following tracer injections into the primary motor cortex (e.g., Strick, 1975, 1976; Kunzle, 1976; Miyata and Sasaki, 1983; Darian-Smith et al., 1990). Clearly, additional experiments will be necessary to define the potentially complex pattern of VPLo and VLo projections to the entire primary motor cortex. Future attempts to explore this issue should include (1) a broad examination of both proximal and distal representations of the primary motor cortex, (2) small tracer injections into electrophysiologically defined sites, and (3) attention to the cytoarchitectonic delineation of VLo from VPLo. 
MI - Sulcus (OM2)
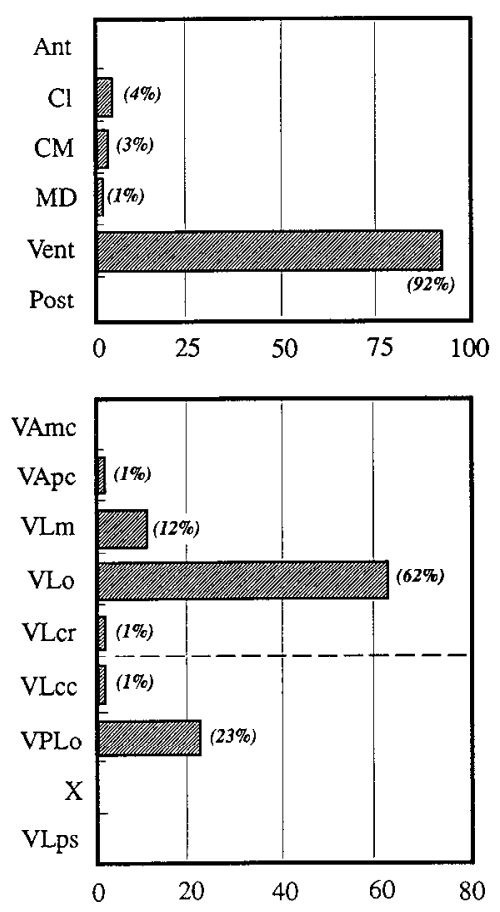

MI - Sulcus (OM4)
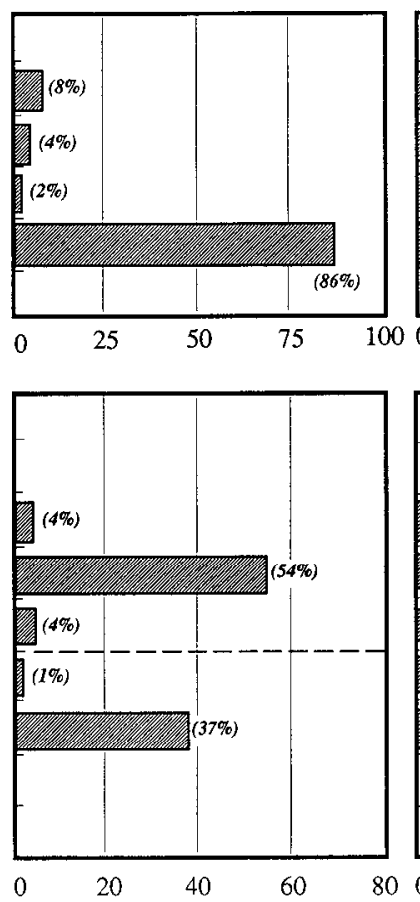

Percent Labeled Neurons
MI - Surface (J14)
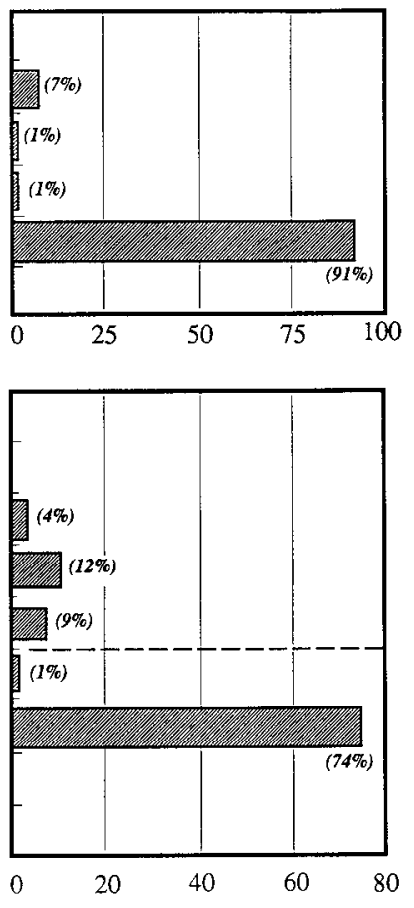

80

Figure 7. Distribution of labeled neurons in the thalamus of each animal. Top, Distribution of labeled neurons within major subdivisions of the thalamus. Note that most of the labeled neurons are found in the ventrolateral thalamus (Vent). Labeled neurons also are found in $C l . C M$, and $M D$. No labeled neurons are found in the anterior nuclear group ( $A n t)$, and less than 1\% are found in the posterior nuclear group (Post). Bottom, Distribution of labeled neurons for each animal within the subdivisions of the ventrolatcral thalamus. The broken line separates thalamic subdivisions receiving pallidal or nigral efferents (above) from those receiving cerebellar efferents (below). Note that the majority of labeled neurons in OM2 and OM4 are located in subdivisions that receive efferents from the basal ganglia. In contrast, the majority of the labeled neurons in $\mathrm{J} 14$ are located in subdivisions that receive efferents from the cerebellum. $V A m c$, ventralis anterior pars magnocellularis.

Basal ganglia and cerebellar pathways to the primary motor cortex

As noted in the introductory remarks, there is general agreement among prior studies that cerebellar and basal ganglia outputs target different subdivisions of the ventrolateral thalamus. One group of subdivisions [i.e., VPLo, VLcc, ventralis lateralis par postrema (VLps), and area X] is the target of efferents from all three deep cerebellar nuclei. Another group of subdivisions [i.e., VLo, VLm, VLcr, and ventralis anterior pars parvocellularis (VApc)] is the target of efferents from the internal segment of the globus pallidus. Our data indicate that these two groups of

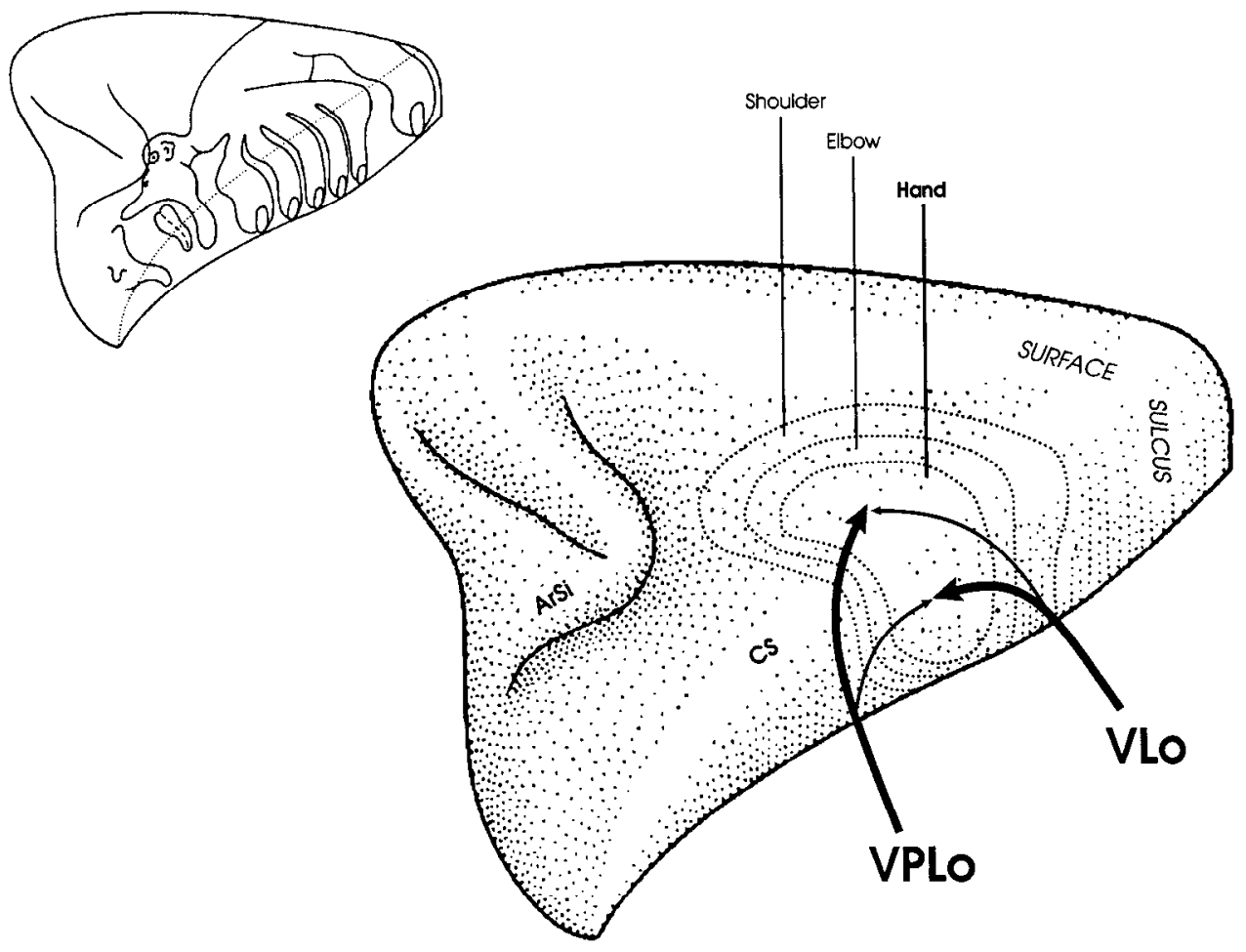

Figure 8. Summary of VPLo and VLo projections to the hand representation in primary motor cortex. Upper left. The classical "simiusculus" of Woolsey et al. (1952) is superimposed on the surface of a lateral view of the hemisphere. The posterior half of the hemisphere has been removed to display the anterior bank of the central sulcus. The $d o t$ ted line indicates the anterior edge of the central sulcus. Lower right, The map of forelimb representation according to Kwan et al. (1978) is superimposed on the lateral view of the hemisphere. The dotted lines on the cortex indicate the location of hand, elbow, and shoulder representation. The relative input from VPLo and VLo to rostral (surface) and caudal (sulcus) regions of the hand representation is indicated by the thickness of the lines with arrows. See Results for details. $C S$, central sulcus; $A r S i$, arcuate sulcus, inferior limb. Adapted from Hepp-Reymond (1988). 


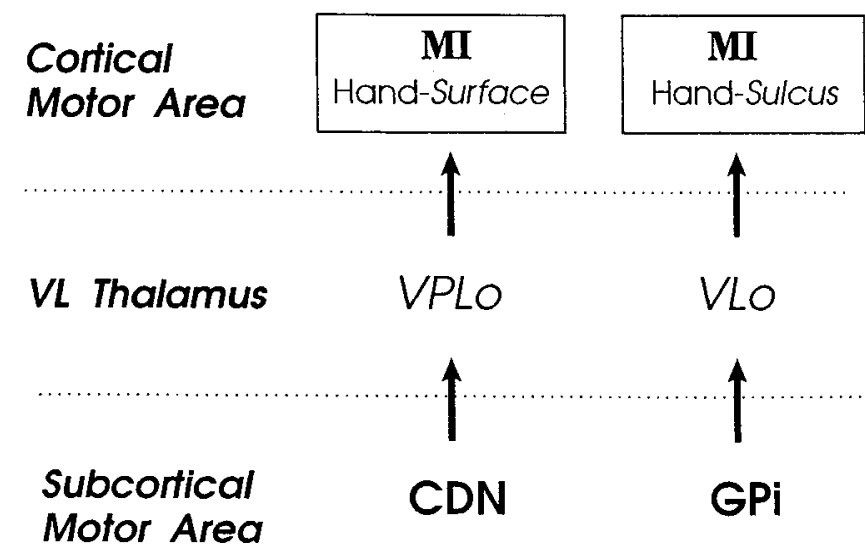

Figure 9. Major pattern of projection from the basal ganglia and the cerebellum to the hand representation of the primary motor cortex. The most substantial subcortical input to the portion of the hand representation on the crest of the precentral gyrus (Hand-Surface) originates from the deep cerebellar nuclei. In contrast, the most substantial input to the portion of the hand representation on the anterior bank of the central sulcus (Hand-Sulcus) originates from the internal segment of the globus pallidus. See Discussion for details. $C D N$, portions of all three deep cerebellar nuclei; $G P i$, internal segment of the globus pallidus; $V L$, ventrolateral.

thalamic subdivisions have largely different patterns of projection to the hand representation of primary motor cortex. VLo, VLm, and VLcr contained the majority of thalamic neurons labeled (62-75\%) after tracer injections into the portion of the hand representation in the bank of the central sulcus. In contrast, VPLo and VLcc contained $75 \%$ of the neurons labeled after tracer injections into the portion of the hand representation on the crest of the precentral gyrus. These results lead to several important conclusions (Fig. 9): (1) the primary motor cortex is "directly" influenced by both cerebello-thalamocortical and pallido-thalamocortical pathways, (2) both subcortical systems innervate regions of the primary motor cortex that are concerned with the generation and control of distal forelimb movements, and (3) a portion of the hand representation on the crest of the precentral gyrus is influenced predominantly by cerebellar outputs, and a portion of the hand representation in the bank of the sulcus is influenced predominantly by pallidal outputs.

Our conclusion that cerebellar efferents influence regions of the primary motor cortex concerned with the generation and control of distal movements is fully consistent with existing concepts about cerebellar connections (e.g., Brooks and Thach, 1981; Asanuma et al., 1983b; Schell and Strick, 1984). On the other hand, our conclusion that a pallidothalamic pathway directly innervates the hand representation of primary motor cortex is a novel anatomical concept. It receives support from the recent physiological results of Jinnai et al. (1989; see also Nambu et al., 1988). These authors found a set of neurons in the ventrolateral thalamus that (1) were monosynaptically inhibited by pallidal stimulation and (2) were antidromically activated from portions of the arm area of the primary motor cortex near the central sulcus. Our conclusions are further supported by the recent finding that neurons in the internal segment of the globus pallidus, as well as in the deep cerebellar nuclei, were labeled after retrograde transneuronal transport of herpes simplex virus from the arm area of the primary motor cortex (Zemanick and Strick, 1990; M. C. Zemanick, P. L. Strick, and R. D. Dix, unpublished observations).
In the preceding discussion, we have emphasized that a given site in the primary motor cortex receives the majority of its thalamic input from subdivisions that are the targets of either cerebellar or pallidal efferents. However, it is important to point out that each site also appears to receive a less substantial input from the other subcortical system. Thus, our data suggest that cerebellar and pallidal systems converge at sites within the primary motor cortex. Whether this convergence is real or apparent is presently unclear. We cannot rule out the possibility that the primary motor cortex may contain functional subdivisions that receive input from only one subcortical system, and that neighboring subdivisions receive a different input.

The literature contains ample evidence for subdivisions within the arm and leg representations of the primate motor cortex (Strick and Preston, 1978a,b, 1982a,b; Lamour et al., 1980; Lemon, 1981; Tanji and Wise, 1981). For example, the primary motor cortex of the squirrel monkey contains two spatially separate representations of the hand (Strick and Preston 1978a,b, $1982 a, b)$. A caudal hand representation receives input predominantly from cutaneous afferents, whereas a rostral representation receives input predominantly from muscle and/or joint afferents. A similar rostrocaudal pattern of afferent segregation has been observed in both the arm and the leg representations of the primary motor cortex in macaques (Lamour et al., 1980; Lemon, 1981; Tanji and Wise, 1981). In one study of the arm area, the noncutaneous zone extended into the upper third of the anterior bank of the central sulcus, and the cutaneous zone was located almost exclusively in the lower half of the sulcus (Lamour et al., 1980; V. A. Jennings, personal communication). However, in another study, the border between the two zones was placed at the junction of the crest of the precentral gyrus and the bank of the sulcus (Lemon, 1981). Thus, the border between the cutaneous and noncutaneous zones of arm representation is not firmly established.

Because no "sensory" mapping was performed in the present study, we are unable to determine the relationship between our injection sites and the afferent zones of motor cortex. It is possible that none of our injection sites were entirely confined to a single functional subdivision of the primary motor cortex. Therefore, the degree to which basal ganglia and cerebellar outputs are differentially routed to or converge upon the cutaneous and noncutaneous zones of the hand representation or other possible functional subdivisions of the primary motor cortex remains to be determined.

\section{Functional implications}

Recent anatomical studies have led to the proposal that the interconnections between the basal ganglia and cerebral cortex form at least five functionally segregated circuits (Alexander et al., 1986). One of these was termed the "motor circuit" and is thought to have a skeletomotor function. Initially, the output limb of the "motor circuit" was thought to be directed only to the supplementary motor area (SMA). However, our observations and those of prior studies (Strick, 1976; Kievit and Kuypers, 1977; Leichnetz, 1986; Ghosh et al., 1987; Jinnai et al., 1989; Matelli et al., 1989; Darian-Smith et al., 1990) suggest that pallidal output also is directed to at least some portions of the primary motor cortex. In addition, recent studies in our laboratory suggest that pallidal output is directed to a premotor area located on the dorsal bank of the cingulate sulcus (CMAd; Holsapple and Strick, 1989; J. W. Holsapple and P. L. Strick, unpublished observations). Thus, at least three cortical motor 
areas are potential targets of basal ganglia output. This raises the possibility that the basal ganglia and cerebral cortex participate in multiple "skeletomotor circuits." Furthermore, because the SMA, CMAd, and primary motor cortex have substantial projections to the spinal cord (e.g., Biber et al., 1978; Murray and Coulter, 1981; Macpherson et al., 1982; Toyoshima and Sakai, 1982; Hutchins et al., 1988; Dum and Strick, 1991a,b), pallido-thalamocortical connections with these cortical areas would enable each skeletomotor circuit to influence the control of movement at the level of the spinal cord.

Finally, our results have important implications for theories regarding the role of the basal ganglia in motor control. Some studies of subjects with basal ganglia disease report prominent disturbances in postural mechanisms involving proximal and axial body musculature (Martin, 1967; for review, see DeLong and Georgopoulos, 1981). Martin (1967) proposed that the basal ganglia are specifically involved in the fixation of proximal joints during the execution of voluntary movements at more distal joints. Based on the results of their recent anatomical study, Matelli et al. (1989) supported this view and proposed that the "cortical fields in which proximal movements are most heavily represented are mainly under the influence of the basal ganglia" (p. 468). On the other hand, they concluded that the "cortical fields in which distal movements were most heavily represented are mainly under the influence of the cerebellum" (p. 468). The anatomical observations reported here offer a different perspective. As noted above, we found that tracer injections into the hand area of the primary motor cortex labeled a large number of neurons in subdivisions of the thalamus that are targets of pallidal output. Based on this result, we propose that a component of basal ganglia output is directed to the hand representation in primary motor cortex (see also Jinnai et al., 1989). Thus, we conclude that the basal ganglia are likely to play a role in the control of distal movements. This conclusion is supported by some of the motor symptoms found in patients with basal ganglia disorders. For example, the classical symptoms of Parkinson's disease include plastic rigidity of the wrist, loss of dexterity in fine finger movement, finger tremor, and micrographia (Schwab and England, 1958). In fact, Schwab and England (1958) indicate that some of the earliest symptoms of this disorder are "peculiar and occasional involuntary posture-holding in a hand" and "loss of usual dexterity with a previously learned motor skill" (p. 494). They noted that these early symptoms may precede the onset of tremor by many years. Thus, there is anatomical, physiological, and clinical evidence that the basal ganglia have an important influence on the control of distal movements. The function of basal ganglia output should no longer be viewed as only postural in nature.

\section{References}

Alexander GE, DeLong MR, Strick PL (1986) Parallel organization of functionally segregated circuits linking basal ganglia and cortex. Annu Rev Neurosci 9:357-381.

Allen GI, Tsukahara N (1974) Cerebrocerebellar communication systems. Physiol Rev 54:957-1006.

Asanuma C, Thach WT, Jones EG (1983a) Cytotectonic delineation of the ventral lateral thalamic region in the monkey. Brain Res Rev 5:219-235.

Asanuma C, Thach WT, Jones EG (1983b) Distribution of cerebellar terminations in the ventral lateral thalamic region of the monkey. Brain Res Rev 5:237-265.

Batton RR, Jayaraman A III, Ruggiero D, Carpenter M (1977) Fastigial efferent projections in the monkey: an autoradiographic study. J Comp Neurol 174:281-306.
Biber MP, Kneisley LW, Lavail JH (1978) Cortical neurons projecting to the cervical and lumbar enlargements of the spinal cord in young and adult rhesus monkeys. Exp Neurol 59:492-508.

Brooks VB, Thach WT (1981) Cerebellar control of posture and movement. In: Handbook of physiology, Sec I, The nervous system, Vol II, Motor control (Brooks VB, ed), pp 877-946. Bethesda, MD: American Physiological Society.

Chan-Palay V (1977) Cerebellar dentate nucleus. Organization, cytology and transmitters. Berlin: Springer.

Conde F (1987) Further studies on the use of the fluorescent tracers fast blue and diamidino yellow: effective uptake area and cellular storage sites. J Neurosci Methods 21:31-43.

Darian-Smith C, Darian-Smith I, Cheema SS (1990) Thalamic projections to sensorimotor cortex in the macaque monkey: use of multiple retrograde fluorescent tracers. J Comp Neurol 299:17-46.

DeLong MR, Georgopoulos AP (1981) Motor functions of the basal ganglia. In: Handbook of physiology, Sec I, The nervous system, Vol II, Motor control (Brooks VB, ed), pp 1017-1061. Bethesda, MD: American Physiological Society.

DeVito JL, Anderson ME (1982) An autoradiographic study of efferents connections of the globus pallidus in Macaca mulatta. Exp Brain Res 46:107-117.

Dum RP, Strick PL (1991a) Premotor areas: nodal points for parallel efferent systems involved in the central control of movement. In: Motor control: concepts and issues (Humphrey DR, Freund H-J, eds.), pp 383-397. London: Wiley.

Dum RP, Strick PL (1991b) The origin of corticospinal projections from the premotor areas in the frontal lobe. J Neurosci 11:667-689.

Evarts EV, Thach WT (1969) Motor mechanisms of the CNS: cerebrocerebellar interrelations. Annu Rev Physiol 31:451-498.

Ghosh S, Brinkman C, Porter R (1987) A quantitative study of the distribution of neurons projecting to the precentral motor cortex in the monkey (M. fascicularis). J Comp Neurol 259:424-444.

Gibson AR, Hansma DI, Houk JC, Robinson FR (1984) A sensitive low artifact TMB procedure for the demonstration of WGA-HRP in the CNS. Brain Res 298:235-241.

Hepp-Reymond M-C (1988) Functional organization of motor cortex and its participation in voluntary movements. In: Comparative primate biology, Vol 4, Neurosciences (Steklis HD, Erwin J, eds.), pp 501-624. New York: Liss.

Holsapple JW, Strick PL (1989) Premotor areas on the medial wall of the hemisphere: input from ventrolateral thalamus. Soc Neurosci Abstr 15:282.

Holsapple JW, Preston JB, Strick PL (1990) Origin of thalamic inputs to the "hand" representation in the primate primary motor cortex. Soc Neurosci Abstr 16:425.

Horne MK, Tracey DJ (1979) The afferents and projections of the ventroposterolateral thalamus in the monkey. Exp Brain Res 36:129141.

Hutchins KD, Martino AM, Strick PL (1988) Corticospinal projections from the medial wall of the hemisphere. Exp Brain Res 71:667672.

Ilinsky IA, Kultas-Ilinsky K (1987) Sagittal cytoarchitectonic maps of the Macaca mulatta thalamus with a revised nomenclature of the motor-related nuclei validated by observations on their connectivity. J Comp Neurol 262:331-364.

Jinnai K, Nambu A, Yoshida S (1989) Activity of thalamic neurons conveying the basal ganglia output to the motor cortex. In: Taniguchi symposia on brain sciences, No 12, Neural programming (Ito M, ed), pp 111-121. Tokyo: Japan Scientific Societies.

Jones EG, Wise SP, Coulter JD (1979) Differential thalamic relationships of sensory-motor and parietal cortical fields in monkeys. J Comp Neurol 183:833-882.

Kalil K (1978) Neuroanatomical organization of the primate motor system: afferent and efferent connections of the ventral thalamic nuclei. In: Multidisciplinary perspectives in event-related brain potential research (Otto OA, ed), pp 112-123. Washington, D.C.: U.S. Environmental Protection Agency.

Kalil K (1981) Projections of the cerebellar and dorsal column nuclei upon the thalamus of the rhesus monkey. J Comp Neurol 195:2550.

Keizer K, Kuypers HGJM, Huisman AM, Dann O (1983) Diamidino yellow dihydrochloride (DY.2HCl): a new fluorescent retrograde neuronal tracer which migrates only very slowly out of the cell. Exp Brain Res 51:179-191.

Kemp JM, Powell TPS (1971) The connexions of the striatum and 
globus pallidus: synthesis and speculation. Philos Trans R Soc Lond [Biol] 262:441-457.

Kievit J, Kuypers HGJM (1972) Fastigial cerebellar projections to the ventrolateral nucleus of the thalamus and the organization of the descending pathways. In: Corticothalamic projections and sensorimotor activities (Frigyesi T, Rinvik E, Yahr MD, eds), pp 91-114. New York: Raven.

Kievit J, Kuypers HGJM (1977) Organization of the thalamo-cortical connexions to the frontal lobe in the rhesus monkey. Exp Brain Res 29:299-322.

Kim R, Nakano K, Jayataman A, Carpenter MB (1976) Projections of the globus pallidus and adjacent structures: an autoradiographic study in the monkey. J Comp Neurol 169:263-290.

Kunzle $H$ (1976) Thalamic projections from the precentral motor cortex in Macaca fascicularis. Brain Res 105:253-267.

Kuo J, Carpenter MB (1973) Organization of pallidothalamic projections in the rhesus monkey. J Comp Neurol 151:201-236.

Kwan HC, Mackay WA, Murphy JT, Wong YC (1978) Spatial organization of precentral cortex in awake primates. II. Motor outputs. J Neurophysiol 41:1120-1131.

Lamour Y, Jennings VA, Solis H (1980) Functional characteristics and segregation of cutaneous and non-cutaneous neurons in monkey precentral motor cortex (MI). Soc Neurosci Abstr 6:158.

Leichnetz GR (1986) Afferent and efferent connections of the dorsolateral precentral gyrus (area 4 , hand/arm region) in the macaque monkey, with comparisons to area 8. J Comp Neurol 254:460-492.

Lemon RN (1981) Variety of functional organization within the monkey motor cortex. J Physiol (Lond) 311:521-540.

Macpherson JM, Wiesendanger M, Marangoz C, Miles TS (1982) Corticospinal neurons of the supplementary motor area (SMA) of monkeys: a single unit study. Exp Brain Res 48:81-88.

Martin JP (1967) The basal ganglia and posture. Philadelphia: Lippencott.

Matelli M, Luppino G, Fogassi L, Rizzolatti G (1989) Thalamic input to inferior area 6 and area 4 in the macaque monkey. J Comp Neurol 280:468-488.

Mehler WR (1971) Idea of a new anatomy of the thalamus. J Psychiatr Res 8:203-217.

Mesulam MM (1982) Tracing neural connections. New York: Wiley.

Miyata M, Sasaki K (1983) HRP studies on thalamocortical neurons related to the cerebellocerebral projection in the monkey. Brain Res 274:213-224.

Murray EA, Coulter JD (1981) Organization of corticospinal neurons in the monkey. J Comp Neurol 195:339-365.

Nambu A, Yoshida S, Jinnai K (1988) Projection on the motor cortex of thalamic neurons with pallidal input in the monkey. Exp Brain Res 71:658-662.

Nauta WJH, Mehler WR (1966) Projections of the lentiform nucleus in the monkey. Brain Res 1:3-42.

Olszewski J (1952) The thalamus of the Macaca mulatta. An atlas for use with the stereotaxic instrument. Basel: Karger.

Orioli PJ, Strick PL (1989) Cerebellar connections with the motor cortex and the arcuate premotor area: an analysis employing retrograde transneuronal transport of WGA-HRP. J Comp Neurol 288: 612-626.

Percheron G (1977) The thalamic territory of cerebellar afferents and the lateral region of the thalamus of the macaque in sterotaxic ventricular coordinates. J Hirnforsch 18:375-400.
Rosene DL, Mesulam MM (1978) Fixation variable in horseradish peroxidase neurohistochemistry. I. The effects of fixation time and perfusion procedures upon enzyme activity. $\mathrm{J}$ Histochem Cytochem $26: 28-39$

Rosene DL, Roy NJ, Davis BJ (1986) A cryoprotection method that facilitates cutting frozen sections of whole monkey brains for histological and histochemical processing without freezing artifact. J Histochem Cytochem 34:1301-1315.

Sato KC, Tanji J (1989) Digit-muscle responses evoked from multiple intracortical foci in monkey precentral motor cortex. J Neurophysiol 62:959-970.

Schell GR, Strick PL (1984) The origin of thalamic inputs to the arcuate premotor and supplementary motor areas. J Neurosci 4:539560.

Schwab RS, England AC (1958) Parkinson's disease. J Chronic Dis 8:488-509.

Sessle BJ, Wiesendanger M (1982) Structural and functional definition of the motor cortex in the monkey (Macaca fascicularis). J Physiol (Lond) 323:245-265.

Stanton G (1980) Topographical organization of ascending cerebellar projections from the dentate and interposed nuclei in Macaca mulatta: an anterograde degeneration study. J Comp Neurol 190:699731.

Strick PL (1975) Multiple sources of thalamic input to the primate motor cortex. Brain Res 88:372-377.

Strick PL (1976) Anatomical analysis of ventrolateral thalamic input to the primate motor cortex. J Neurophysiol 39:1020-1031.

Strick PL, Preston JB (1978a) Multiple representation in the primate motor cortex. Brain Res 154:366-370.

Strick PL, Preston JB (1978b) Sorting of somatosensory afferent information in primate motor cortex. Brain Res 156:364-368.

Strick PL, Preston JB (1982a) Two representations of the hand in area 4 of a primate. I. Motor output organization. J Neurophysiol 48:139 149

Strick PL, Preston JB (1982b) Two representations of the hand in area 4 of a primate. II. Somatosensory input organization. J Neurophysiol 48:150-159.

Suzuki H, Azuma M (1976) A glass-insulated ‘Elgiloy' microelectrode for recording unit activity in chronic monkey experiments. Electroencephalogr Clin Neurophysiol 41:93-95.

Tanji J, Wise SP (1981) Submodality distribution in sensorimotor cortex of the unanesthetized monkey. J Neurophysiol 45:467-481.

Toyoshima K, Sakai H (1982) Exact cortical extent of the origin of the corticospinal tract (CST) and the quantitative contribution to the CST in different cytoarchitectonic areas. A study with horseradish peroxidase in the monkey. J Hirnforsch 23:257-269.

Wiesendanger R, Wiesendanger M (1985) The thalamic connections with medial area 6 (supplementary motor cortex) in the monkey (Macaca fascicularis). Exp Brain Res 59:91-104.

Woolsey CN, Settlage PH, Meyer DR, Sencer W, Pinto-Hamuy T, Travis AM (1952) Patterns of localization in precentral and "supplementary" motor areas and their relation to the concept of a premotor area. Nerv Ment Dis 30:238-264.

Zemanick MC, Strick PL (1990) Retrograde and anterograde transneuronal transport of HSV-1 in the primate motor system. Soc Neurosci Abstr 16:425. 